\title{
Bimetallic Ion Exchange Material Titanium Tin Molybdate as an Efficient and Eco-friendly Adsorbent for the Removal of Methylene Blue from Aqueous Solution
}

\author{
M A Dhanitha ${ }^{1}$, C Janardanan ${ }^{2}$ \\ ${ }^{1,2}$ Post Graduate and Research Department of Chemistry, Sree Narayana College, Kannur, Kerala-670007, \\ India
}

\begin{abstract}
The objective of current study is to explore the potential use of a bimetallic inorganic cation exchanger, titanium tin molybdate (TSM) for the removal of methylene blue from aqueous solution. TSM was synthesized by co-precipitation method, surface morphology was studied by using SEM and other physicchemical characteristics were done using FTIR, XRD, TGA etc. The exchanger shows high ion exchange capacity of $1.56 \mathrm{meqg}^{-1}$ as well as good chemical and thermal stability. The distribution studies of various metal ions on this material in different solvent systems showed that it was highly selective for $P b(I I), C d(I I)$ and $\mathrm{Cu}(I I)$. The UV-Vis DRS studies exposed the enhanced adsorption capability of the material towards methylene blue (MB), a hazardous organic pollutant. Batch studies were performed to evaluate various experimental parameters such as contact time, $\mathrm{pH}$, adsorbent dosage, initial concentration of $M B$ and temperature on the adsorption of $M B$. The isotherm studies showed that the equilibrium data were mathematically fitted to Langmuir equation. The results of kinetic studies showed that the process follows pseudo-second order kinetics. The entire studies revealed that the new exchanger TSM could be employed as an effective and economically viable adsorbent in wastewater treatment for the removal of hazardous organic dye.
\end{abstract}

Keywords: Bimetallic ion exchanger, distribution studies, methylene blue, equilibrium studies etc.

\section{Introduction}

Environmental problem caused by toxic organic pollutants from the domestic and industrial output is now the subject of considerable concern from environmental remediation point of view [1]. Many industries such as textile, rubber, leather, paper, cosmetics, plastics, food, and pulp use synthetic organic dyes to colour their products. Dyes are extensively used in the textile industry because of their wide variety of color shades, ease of application and minimal energy consumption. Disposal of these dyes into the environment causes pollution and serious damage, and also they are toxic to some aquatic organisms [2]. Among various cationic dyes, methylene blue has wider applications, which include coloring paper, temporary hair colorant, dyeing cottons, wools, and coating for paper stock, etc[3-5]. Though methylene blue is not strongly hazardous, it can cause some harmful effects. Removal of dyes from polluted effluent is an essential task for environmental protection. Due to low biodegradability of dyes, a conventional biological treatment process is not very effective in treating a dye wastewater.

The removal of coloured and colourless organic pollutants from industrial wastewater is considered an important application of adsorption processes using a suitable adsorbent [6]. There is growing interest in using low cost and eco-friendly materials for the adsorption of dyes. Adsorption with ion exchanger is one of the best methods for the removal of dyes from wastewater [7]. For a successful scale-up of such a process; we prepared a new bimetallic inorganic cation exchanger titanium tin molybdate, having enhanced adsorption capability towards MB. Kinetic studies are essential since they describe the adsorbate uptake rate, which in turn controls the residence time in the adsorbent-solution interface. Experiments of dye sorption kinetics and equilibrium were performed in batch conditions. Many factors could affect the adsorption rate of the dye solution. In this study, adsorbent dosage, initial dye concentration, $\mathrm{pH}$ and agitation time were investigated.

\section{Reagents and chemicals:}

\section{Experimental}

Titanium trichloride, stannic chloride and sodium were obtained from Loba Chemie (India). All other chemicals and reagents used were of analytical grade.

\section{Instrumentation:}

pH measurements were performed using an ELICO LI613 pH meter. Spectrophotometry was done on a UV- Visible Spectrophotometer model JASCO V660 with diffuse reflectance accessory (integrated sphere). IR studies were made using an FTIR spectrometer model Thermo Nicolet Avtar370and thermogram was run on 
Perkin Elmer Diamond TG/DTA Analyzer. X-ray diffractometer BrukerAXS D8 Advance for X-ray diffraction studies and an electric temperature controlled shaker was used for shaking. Chemical composition was determined using EDS. A glass column was used for column operations.

\section{Synthesis of the exchanger:}

Different samples of TSM were prepared by adding $0.05 \mathrm{M}$ sodium molybdate solution to a mixture of $0.05 \mathrm{M}$ titanium trichloride solution and $0.05 \mathrm{M}$ stannic chloride solution in different volume ratios with intermittent shaking of the mixture and keeping the $\mathrm{pH}$ at 1.0 as given in table 1 . The precipitates were filtered, washed with deionized water and dried. The exchangers were then converted in to the $\mathrm{H}^{+}$form by treating with $1 \mathrm{M}$ nitric acid for $24 \mathrm{hrs}$ with occasional shaking and intermittent changing of acid. Then the samples were washed with deionized water to remove the excess acid, dried and sieved to obtain particles of 60-100 mesh.

Properties like ion exchange capacity (IEC), chemical resistivity and $\mathrm{pH}$ titration studies, distribution studies and effect of temperature on IEC were carried out as reported earlier [8].

\section{Application of TSM for the Removal of dyes:}

Batch experiments were performed according to Mahanta et al [9]. The initial and final concentrations of methylene blue solutions were determined by measuring absorbance at $664 \mathrm{~nm}$ using UVvisible absorption spectroscopy. Methylene blue solutions (10 mL) of different concentrations (20 ppm to $50 \mathrm{ppm})$ were mixed with $0.2 \mathrm{~g}$ of material and kept for $2 \mathrm{hrs}$ and their absorbance was measured. The effect of $\mathrm{pH}(2-12)$, contact time (10-180), and adsorbent dosage (100-500mg), temperature $\left(30-60^{\circ} \mathrm{C}\right)$ and initial concentration of $\mathrm{MB}(10-$ $50 \mathrm{ppm}$ ) were carried out. The percentage of removal of dyes was calculated using the following formula,

Removal $(\%)=\frac{C i-C e}{C i} \times 100$

Where, $\mathrm{Ci}$ is the initial dye concentration and $\mathrm{Ce}$ is the equilibrium dye concentration in $\mathrm{mLL}^{-1}$.

\section{Synthesis and characterization of the exchanger}

\section{Results And Discussion}

Samples of titanium tin molybdate of various compositions have been synthesized, but TSM 3 obtained as brown granular solid having maximum ion exchange capacity, $1.56 \mathrm{meqg}^{-1}$ was selected for detailed studies (Table1). The composition of TSM 3 obtained from EDS method was found as Ti:Sn:Mo::1:1.8:2.1.

FTIR spectra (Fig. 1(a)) shows broad band in the region $\sim 3604 \mathrm{~cm}^{-1}$ attributed to symmetric and asymmetric -OH stretching, while band at $\sim 1622 \mathrm{~cm}^{-1}$ is due to $\mathrm{H}-\mathrm{O}-\mathrm{H}$ bending [10]. Bands at $\sim 2368 \mathrm{~cm}^{-1}$, $\sim 950 \mathrm{~cm}^{-1}$ and $\sim 412 \mathrm{~cm}^{-1}$ express the presence of Ti-O, Sn-O and Mo-O groups respectively [11-12]. The X-ray diffractogram (Fig. 1(b)) of the material does not exhibit any sharp peak indicating TSM to be an amorphous material [13]. The thermogram of TSM (Fig. 1(c)) suffers a first weight loss up to $150^{\circ} \mathrm{C}$, attributed to the loss of moisture and hydrated water while the second weight loss observed at around $284^{\circ} \mathrm{C}$ due to condensation of exchangeable hydroxyl groups take place which is the usual behavior of inorganic ion exchangers. Then the sample is almost stable up to $752^{\circ} \mathrm{C}$. The Scanning Electron Microscope image (Fig. 1(d)) of TSM explains that the particles were broad in size range, having an irregular shape and no sign of crystalline structure [14].

$\mathrm{pH}$ titration studies (Fig. 2(a)) using $\mathrm{NaCl} / \mathrm{NaOH}, \mathrm{KCl} / \mathrm{KOH}$ systems show nearly monofunctional behaviour indicating only one ionizing group . The exchange capacity obtained from the curve is in agreement with that obtained by the column method. The sodium ion exchange capacity decreases (Fig. 2(b)) slightly with temperature and the sample retained prominent capacity up to $600^{\circ} \mathrm{C}$ which can be explained with the obtained thermogram also.

The distribution studies of metal ions in water and various other electrolytes (Table 2) showed that the exchanger has very high affinity towards $\mathrm{Pb}^{2+}$ ions in comparison to other metal ions studied. The selectivity was found to be in the order $\mathrm{Pb}^{2+}>\mathrm{Cu}^{2+}>\mathrm{Cd}^{2+}>\mathrm{Ca}^{2+}>\mathrm{Co}^{2+}>\mathrm{Zn}^{2+}>\mathrm{Mn}^{2+}>\mathrm{Mg}^{2+}>\mathrm{Al}^{3+}>\mathrm{Ni}^{2+}>\mathrm{Bi}^{3+}>\mathrm{Hg}^{2+}$. The effect of electrolyte concentrations on distribution coefficients showed that the value decreases with increase in electrolyte concentrations (Table 2).

\section{Adsorptive removal of Dyes:}

Methylene blue (MB) serves as model compound of the harmful and water soluble organic pollutants, which is widely used in the textile industries and harmful to the environment. The adsorption of MB onto the exchanger was studied by using UV-visible spectroscopy under batch conditions. The adsorption experiments were carried out by agitating $200 \mathrm{mg}$ of the adsorbent with $10 \mathrm{~mL}$ of $40 \mathrm{ppm}$ solution of methylene blue [15]. The adsorption of MB on exchanger was confirmed by UV-Visible Diffuse Reflectance Spectroscopy (Fig. 3(a)). MB shows an intense absorption peak in the visible region at $660 \mathrm{~nm}$ which corresponds to its maximum absorption peak as monomer. Concentrations of methylene blue (MB) in the supernatant solutions were 
estimated by measuring absorbance at maximum wavelengths of the dye ( $\lambda \max =660 \mathrm{~nm})$. Fig.3(b) illustrates that the original peaks of methylene blue gets disappeared after its treatment with the adsorbent.

\subsection{Effect of various experimental parameters on dye removal}

Agitation time is an important parameter in concern with dye adsorption. To study the effect of reaction time on the adsorption of MB, 200mg of TSM was shaken with $10 \mathrm{ml}$ of 40ppm MB dye solutions at room temperature, keeping the $\mathrm{pH}$ of the medium neutral. Adsorption capability was measured by taking optical density at different time intervals using UV-Vis DRS.The extent of removal of Methylene Blue by TSM was found to increase, reach a maximum value with increase in contact time (Fig. 4(a)). In some cases it almost become constant with increase in contact time, after $120 \mathrm{~min}$. based on these results, $120 \mathrm{~min}$ was taken as the equilibrium time in adsorption experiments. Similar results have been reported in literature for removal of dyes [16-17].

The $\mathrm{pH}$ of the dye solution is likely to affect the adsorption of the dye; hence the effect of $\mathrm{pH}$ on the rate of adsorption of MB dye was investigated in the $\mathrm{pH}$ range 2-12. The results are presented in Fig. 4(b). The $\mathrm{pH}$ was measured after the addition of the exchanger. The results showed that the adsorption was less at lower $\mathrm{pH}$ values, whereas maximum adsorption was seen at higher $\mathrm{pH}$ values $(\mathrm{pH}=10)$. It indicated that the interaction of $\mathrm{MB}$ on exchanger was less at lower $\mathrm{pH}$ due to the presence of high concentration of $\mathrm{H}^{+}$ions on the surface of exchanger competing with methylene blue for adsorption site in the adsorbent, whereas at higher $\mathrm{pH}$ electrostatic, repulsion between positively charged methylene blue and the surface of adsorbent was lowered. Consequently, removal efficiency was increased at higher $\mathrm{pH}$.

Adsorbent dosage is an important factor which must be carefully optimized during waste water treatment. The effect of adsorbent dosage (100-500mg) was studied on 40ppm concentration of dye solution at room temperature and neutral $\mathrm{pH}$, and the results were accessible in Fig. 4(c). Removal of dye with increasing adsorbent dosage was observed which was due to the availability of more reactive sites for adsorption [18].

Experiments were conducted with different concentrations of $\mathrm{MB}$ in the presence of $200 \mathrm{mg}$ of exchanger for $2 \mathrm{hrs}$, and its effect on sorption of dye was determined, shown in Fig. 4(d). This study revealed that the percentage removal of dye decreases at higher concentration. The enhanced removal at low concentration could be due to the faster movement of dye into the activated sites of exchanger. However, in higher concentration $(50 \mathrm{ppm})$ the removal rate was decreased $(29.70 \%)$ because the dye molecules needed to diffuse to the adsorbent sites by intraparticle diffusion. In addition, steric repulsion between the solute molecules could slow down the adsorption process and thereby decrease the removal rate [19].

Temperature has important effects on the adsorption process. As the temperature increase, rate of diffusion of adsorbate molecules across the external boundary layer and interval pores of the adsorbent particle increase. Changing to temperature will change the equilibrium capacity of the adsorbent for particular adsorbate [20-21]. Fig. 5 shows effects of different temperatures for Methylene Blue adsorption on TSM. The removal of Methylene Blue by adsorption on TSM increases slightly from 49.29 to $90.61 \%$ by increasing temperature of the solution from 30 to $60^{\circ} \mathrm{C}$, indicating the process to be endothermic.

\subsection{Adsorption isotherms}

For solid-liquid adsorption system, adsorption isotherm is important model in the description of adsorption behavior. When the adsorption reaction reaches equilibrium state, the adsorption isotherm can indicate the distribution of dye molecules between the solid phase and the liquid phase [22]. It is significant for understanding the adsorption behavior to identify the most appropriate adsorption isotherm model. In this paper, Langmuir and Freundlich isotherms were employed to investigate the adsorption behaviour. Adsorption isotherm was studied at four different temperatures viz 303, 313, 323 and 333K.

\subsubsection{Langmuir isotherm}

Langmuir isotherm is rested on the assumption that adsorption occurs at specific homogenous sites within the adsorbent. Once an adsorbate molecule occupies a site, no further adsorption can take place. Thus, an equilibrium value can be reached and the saturated monolayer curve can be express in the equation below which has been successful for the explanation of monolayer adsorption. The linear form of Langmuir equation is given as,

$$
\frac{C_{e}}{q_{e}}=\frac{1}{q_{\max } K_{L}}+\frac{C_{e}}{q_{\max }}
$$

where $\mathrm{q}_{\max }$ is the maximum or monolayer adsorption capacity of the adsorbent $\left(\mathrm{mgg}^{-1}\right)$ and $\mathrm{K}_{\mathrm{L}}$ is the Langmuir adsorption constant $\left(\mathrm{Lmg}^{-1}\right)$, which is related to the free energy of adsorption. Plots of $\mathrm{C}_{\mathrm{e}} / \mathrm{q}_{\mathrm{e}}$ against $\mathrm{C}_{\mathrm{e}}$ at different temperatures are shown in Fig. 6(a). The maximum adsorption capacity, $\mathrm{q}_{\max }$ and Langmuir constant, $\mathrm{K}_{\mathrm{L}}$ were calculated from the slopes and intercepts of the plots respectively. Values obtained for the 
adsorption of methylene blue onto the adsorbent are presented in Table 3. The correlation coefficient values $\left(\mathrm{R}^{2}\right.$ $>0.9995$ ) (Table 3) show strong positive correlation indicating that adsorption follows Langmuir isotherm.

\subsubsection{Freundlich isotherm}

The Freundlich isotherm model is used to describe heterogeneous adsorption process i.e adsorption which takes place on a heterogeneous surface through a multilayer adsorption mechanism. Freundlich isotherm is expressed by the equation,

$\log q_{e}=\log K_{F}+\frac{1}{n} \log C_{e}$

Where, $\mathrm{K}_{\mathrm{F}}$ and $\mathrm{n}$ are Freundlich constants that are related to the adsorption capacity and adsorption intensity respectively. The values of $K_{F}$ and $n$ were obtained from the linear plots of $\log _{e_{e}}$ versus $\log q_{e}$. The slope, $1 / \mathrm{n}$, ranging between 0 and 1 is a measure of adsorption intensity or surface heterogeneity. The plots of the linear form of Freundlich isotherm curves at different temperatures are presented in Fig. 6(b). The Freundlich parameters and correlation coefficients $\left(\mathrm{R}^{2}\right)$ evaluated from the plots are listed in Table 1.

\subsection{Adsorption Kinetics}

For the examination of the controlling mechanisms of adsorption process, such as chemical reaction, diffusion control and mass transfer [23-24], several kinetic models are used to test the experimental data. For the present study, two kinetic models were applied in order to understand the mechanism of adsorption of the dye onto the adsorbent. The models are the pseudo-first order and pseudo-second-order models. The pseudo-first order kinetic model can be represented by Lagergren rate equation [23],

$$
\log \left(\mathrm{q}_{\mathrm{e}}-\mathrm{q}_{\mathrm{t}}\right)=\log \mathrm{q}_{\mathrm{e}}-\frac{K_{1}}{2.303} t
$$

where $\mathrm{q}_{\mathrm{e}}$ and $\mathrm{q}_{\mathrm{t}}$ represent the amounts of dye adsorbed $\left(\mathrm{mgg}^{-1}\right)$ at equilibrium and at any time, $\mathrm{t}(\mathrm{min})$, $\mathrm{k}_{1}$ is the rate constant $\left(\mathrm{min}^{-1}\right)$. The values of $\mathrm{q}_{\mathrm{e}}$ and $\mathrm{k}_{1}$ were deduced from the intercepts and slopes of the linear plots of $\log \left(\mathrm{q}_{\mathrm{e}}-\mathrm{q}_{\mathrm{t}}\right)$ against $\mathrm{t}$ (Fig. 7(a)). For the present study however, Lagergren pseudo-first order kinetics parameters (Table 4) was not proved to be effective in representing the experimental kinetic data for the entire adsorption period and at all dye concentrations. Report of non fitting of pseudo-first order kinetic to adsorption has been published [25]. This result suggests that the kinetics of MB adsorption onto TSM cannot be accounted for using the pseudo-first order model and hence not a chemisorption process.

$$
\frac{t}{q_{t}}=\frac{1}{K_{2} q_{e}^{2}}+\frac{1}{q_{B}} t \quad \text { (6) }
$$

where $\mathrm{k}_{2}$ is the rate constant of pseudo-second order adsorption $\left(\mathrm{gmg}^{-1} \mathrm{~min}^{-1}\right)$. Fig. 7(b) shows pseudosecond order plots for the adsorption process for five different concentrations of the dye. $K_{2}$ and $\mathrm{q}_{\mathrm{e}}$ values were determined from the intercepts and slopes of the linear plots of respectively (Figure 7(b)). Calculated values of the adsorption capacity $\mathrm{q}_{\mathrm{e}},\left(\mathrm{mgg}^{-1}\right)$ gave a good correlation coefficient $\left(\mathrm{R}^{2}>0.99\right)$ (Table 4). Thus adsorption process could be said to follow pseudo-second order kinetic model for all concentrations of the dye. The applicability of the pseudo-second order model suggests that chemical reaction might be responsible for adsorption of MB onto TSM. The kinetics of adsorption of many dye species onto various materials have been reported to conform to pseudo-second order kinetic model [27-28].

\section{Figures And Tables}

Table1: Synthesis and properties of various samples of exchanger using $0.05 \mathrm{M}$ solutions each.

\begin{tabular}{|c|c|c|c|c|}
\hline Sample & $\begin{array}{c}\text { Volume } \\
\text { ratio }\end{array}$ & $\mathrm{pH}$ & Appearance & $\begin{array}{l}\text { IEC for } \mathrm{Na}^{+} \\
(\mathrm{meq} / \mathrm{g})\end{array}$ \\
\hline TSM 1 & $1: 1: 1$ & 1 & & 0.95 \\
TSM 2 & $1: 1: 2$ & 1 & All forms & 1.02 \\
TSM 3 & $1: 2: 3$ & 1 & Brown & 1.56 \\
TSM 4 & $1: 2: 4$ & 1 & granular & 1.20 \\
TSM 5 & $2: 1: 4$ & 1 & solids & 1.19 \\
\hline
\end{tabular}

Table 2: Distribution coefficients in various electrolytes

\begin{tabular}{l|l|l|l|l|l|l|l}
\hline \multirow{3}{*}{ Cations } & \multicolumn{2}{|l|}{ Distribution coefficients $\left(\mathrm{K}_{\mathrm{d}}\right)$} \\
\cline { 2 - 7 } & $\mathrm{DMW}$ & $\mathrm{HNO}$ & $0.01 \mathrm{M}$ & $0.1 \mathrm{M}$ & $0.001 \mathrm{M}$ & $0.01 \mathrm{M}$ & $0.1 \mathrm{M}$ \\
\cline { 2 - 7 } & & $0.001 \mathrm{M}$ & 24.56 & 8.65 & 52.43 & 26.34 & 9.45 \\
$\mathrm{Al}^{3+}$ & 72.27 & 48.02 & 2.87 & $\mathrm{NS}$ & 15.98 & 3.12 & $\mathrm{NS}$ \\
$\mathrm{Bi}^{3+}$ & 23.46 & 12.23 & 35.85 & 13.25 & 59.41 & 38.87 \\
$\mathrm{Ca}^{2+}$ & 99.23 & 56.35 & 72.78 & 35.79 & 145.67 & 85.54 & 47.54 \\
$\mathrm{Cd}^{2+}$ & 211.0 & 128.36 & &
\end{tabular}


Bimetallic Ion Exchange Material Titanium Tin Molybdate as an Efficient and Eco-friendly ....

\begin{tabular}{l|l|l|l|l|l|l|l}
$\mathrm{Co}^{2+}$ & 96.66 & 53.12 & 23.65 & 2.43 & 58.76 & 29.87 & 3.66 \\
$\mathrm{Cu}^{2+}$ & 317 & 173.16 & 89.74 & 26.85 & 184.26 & 93.34 & 31.65 \\
$\mathrm{Hg}^{2+}$ & $\mathrm{NS}$ & $\mathrm{NS}$ & $\mathrm{NS}$ & $\mathrm{NS}$ & $\mathrm{NS}$ & $\mathrm{NS}$ & $\mathrm{NS}$ \\
$\mathrm{Mg}^{2+}$ & 75 & 45.67 & 21.45 & 5.67 & 51.05 & 25.23 & 6.06 \\
$\mathrm{Mn}^{2+}$ & 87.87 & 60.67 & 24.98 & 6.32 & 64.34 & 28.35 & 8.43 \\
$\mathrm{Ni}^{2+}$ & 63 & 48.94 & 19.79 & 2.12 & 53.12 & 21.76 & 3.06 \\
$\mathrm{~Pb}^{2+}$ & 980 & 754.67 & 487.36 & 287.65 & 767.49 & 494.44 & 292.43 \\
$\mathrm{Zn}^{2+}$ & 90 & 50.45 & 16.89 & $\mathrm{NS}$ & 57.26 & 18.53 & 18.45
\end{tabular}

Table 3: Parameters for Langmuir and Freundlich isotherms

\begin{tabular}{|c|c|c|c|c|c|c|}
\hline \multirow{2}{*}{$\mathrm{T}(\mathrm{K})$} & \multicolumn{2}{|c|}{ Langmuir isotherm } & \multicolumn{2}{|c|}{ Freundlich isotherm } & $\mathrm{R}^{2}$ \\
\cline { 2 - 6 } & $\begin{array}{c}\mathrm{q}_{\max } \\
(\mathrm{mg} / \mathrm{g})\end{array}$ & $\begin{array}{c}\mathrm{K}_{\mathrm{L}} \\
(\mathrm{L} / \mathrm{mol})\end{array}$ & $\mathrm{R}^{2}$ & $\mathrm{~K}_{\mathrm{f}}$ & $\mathrm{n}$ & \\
\hline 303 & 1.1601 & 131.68 & 0.9997 & 0.0154 & 2.2050 & 0.7257 \\
313 & 0.9961 & 162.36 & 0.9996 & 0.0363 & 2.0963 & 0.8021 \\
323 & 1.0590 & 185.04 & 0.9999 & 0.0466 & 2.0898 & 0.8029 \\
333 & 1.1498 & 186.51 & 0.9999 & 0.0698 & 2.3444 & 0.8058 \\
\hline
\end{tabular}

Table 4: Kinetic parameters for the adsorption of Methylene blue onto TSM

\begin{tabular}{|l|c|c|c|c|c|}
\hline \multicolumn{2}{|c|}{ First order } & \multicolumn{3}{|c|}{ Second order } \\
\hline $\mathrm{K}_{1}$ & $\begin{array}{c}\mathrm{q}_{\mathrm{e}} \\
(\mathrm{m} / \mathrm{L})\end{array}$ & $\mathrm{R}^{2}$ & $\mathrm{~K}_{2}$ & $\begin{array}{c}\mathrm{q}_{\mathrm{e}} \\
(\mathrm{mg} / \mathrm{L})\end{array}$ & $\mathrm{R}^{2}$ \\
\hline 0.0046 & 3.49 & 0.8279 & 0.0033 & 4.53 & 0.9888 \\
\hline
\end{tabular}
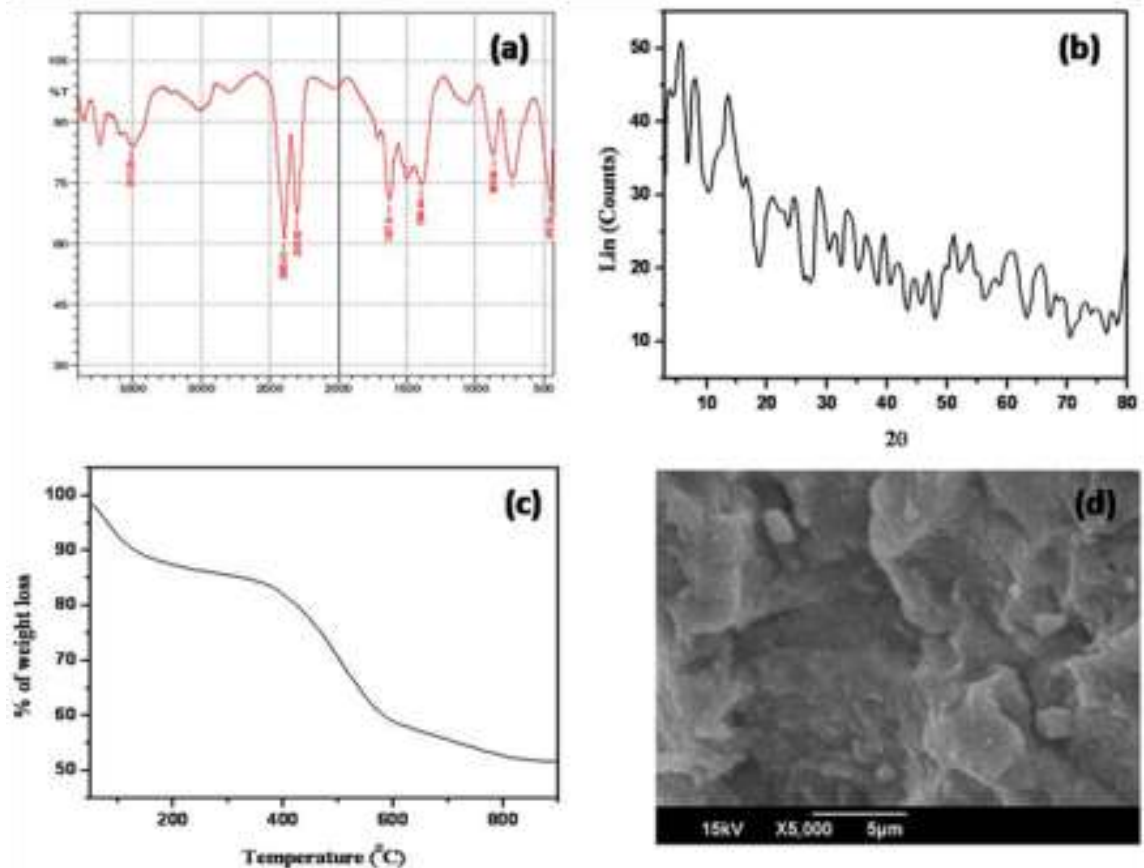

Figure1: (a) FTIR, (b) XRD, (c) TGA and (d) SEM of TSM
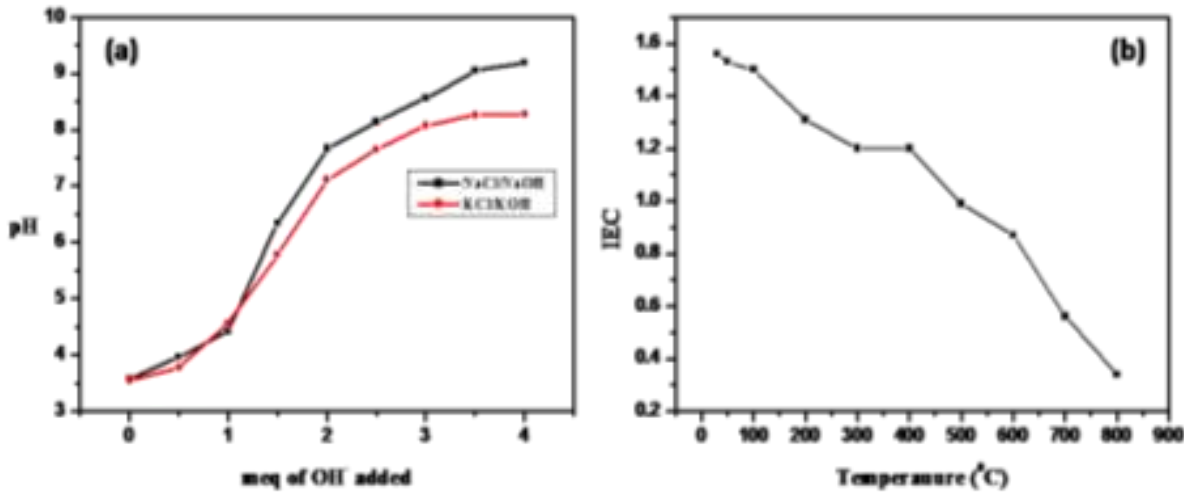

Figure 2: (a) pH titration curves and (b) Effect of temperature on IEC 

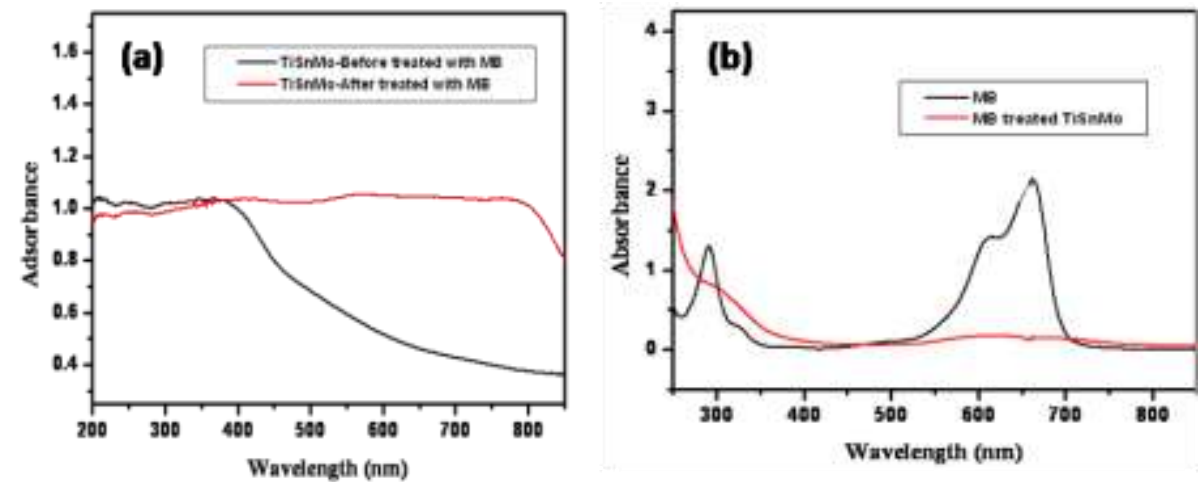

Figure 3: UV-Visible Spectra of (a) TSM before and after treatment with MB and (b) pure MB and MB after treatment with TSM
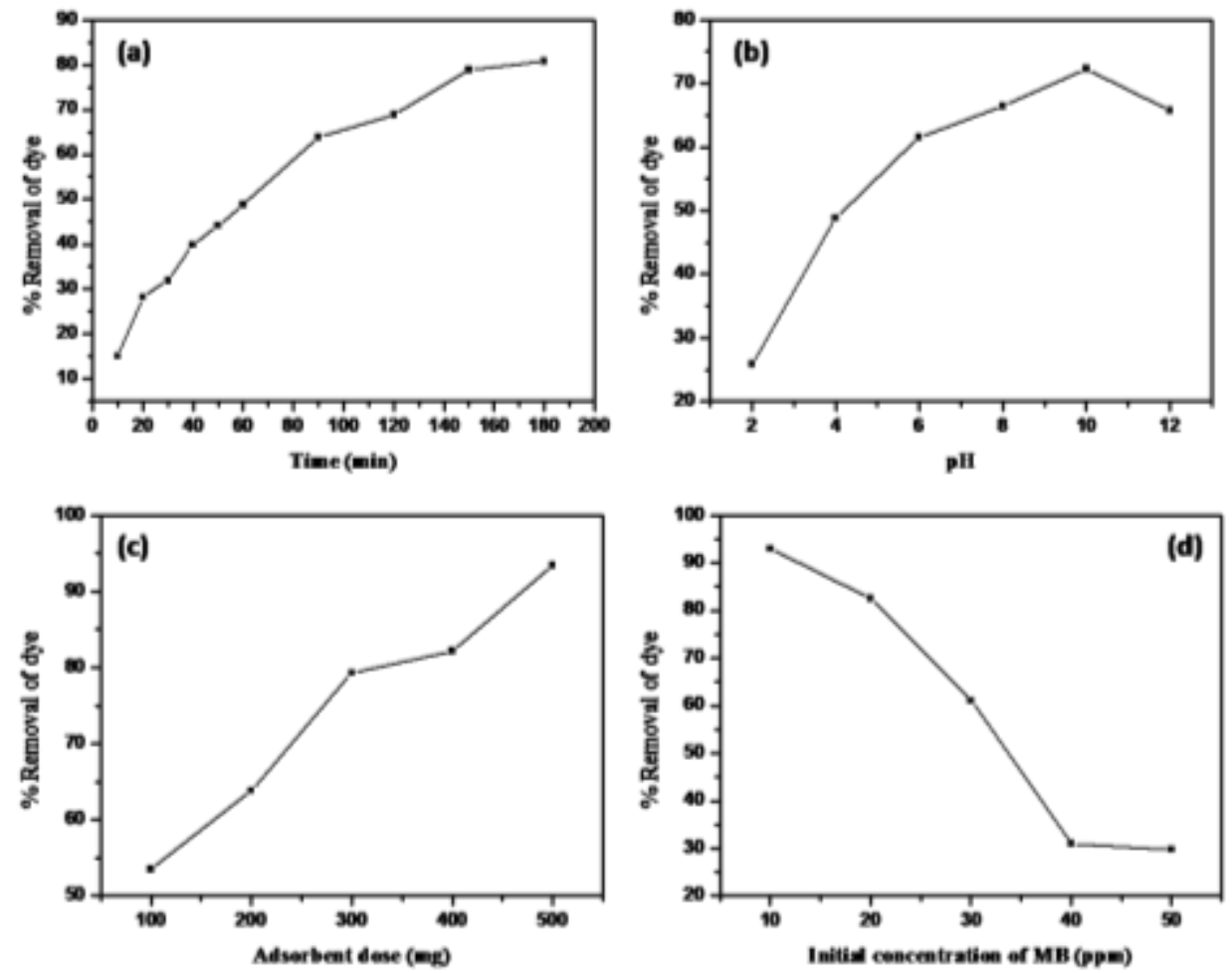

Figure 4: Effect of (a) Reaction time, (b) pH, (c) Adsorbent dose and (d) Initial concentration of MB on the removal of MB

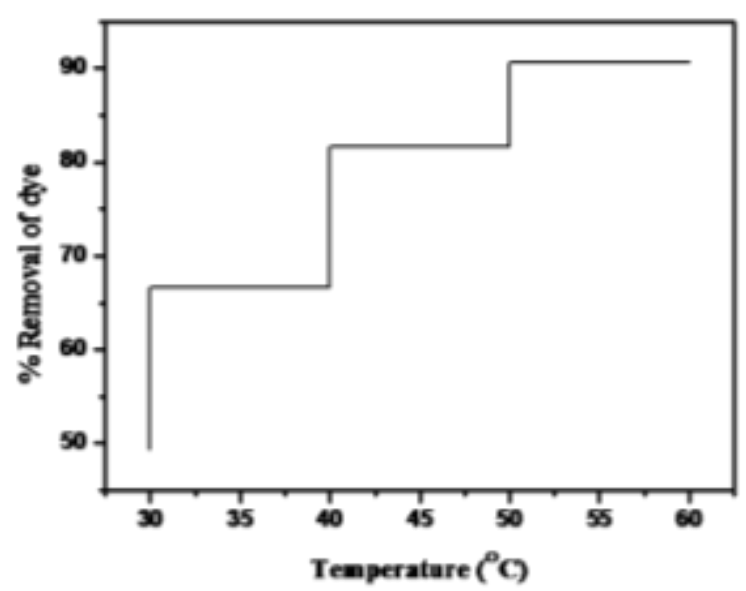

Figure 5: Effect of temperature on the removal of MB 

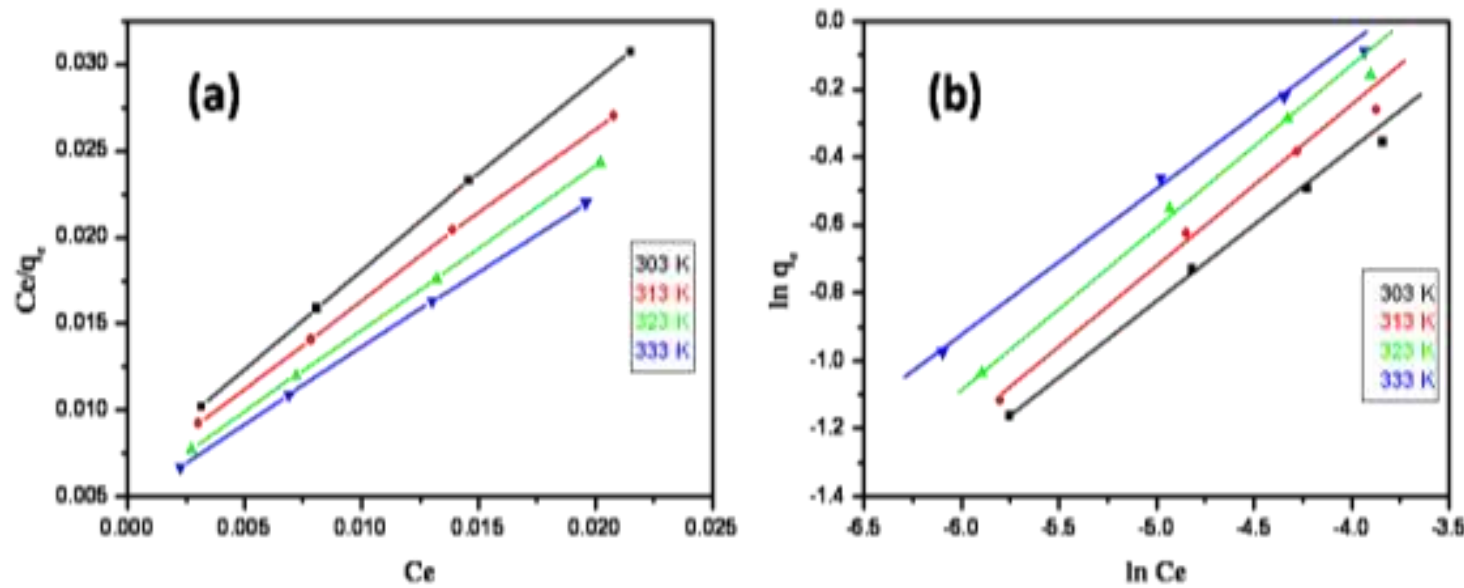

Figure 6: (a) Langmuir isotherm and (b) Freundlich isotherm
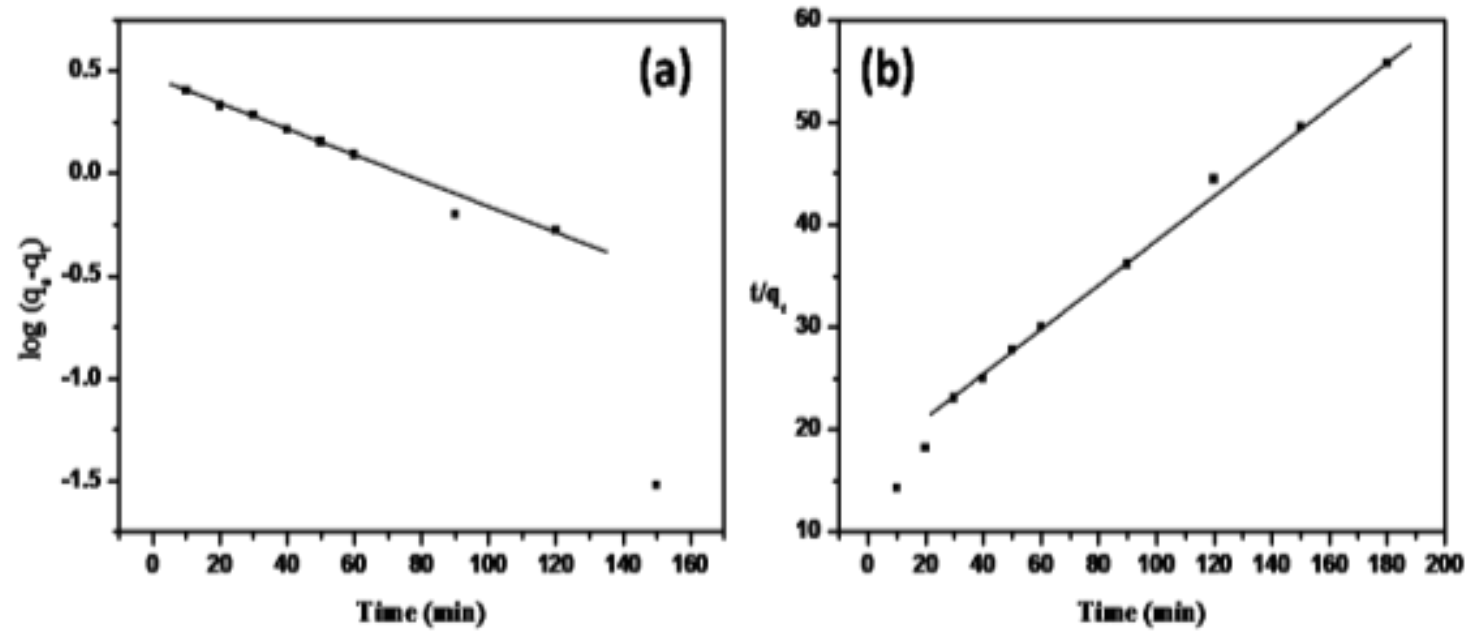

Figure 7: (a) First order kinetics and (b) Second order kinetics

\section{Conclusion}

Adsorption studies indicate that the exchanger titanium tin molybdate is an effective adsorbent for the removal of methylene blue dye from aqueous solution. The isotherm models such as Langmuir and Freundlich were studied, amongst them Langmuir equation showed the more applicability to the experimental data than Freundlich isotherm. The rate of adsorption was studied using pseudo first order and second order kinetic equations, and it was found that the data fits better with pseudo-second order model. The whole studies revealed that the new exchanger TSM could be employed as an effective and economically viable adsorbent in wastewater treatment for the removal of toxic heavy metal ions and hazardous organic dyes.

\section{Acknowledgement}

Author acknowledges the Council of Scientific and Industrial Research for awarding Junior Research Fellowship and STIC, Cochin, School of Chemical Sciences, M G University, Kottayam for providing technical facilities.

\section{Reference}

[1]. Rakshit Ameta, Daksha Sharma and Mamta Ordia, hotocatalytic degradation of crystal violet using nickel containing polytungstometalate, Scientific Reviews and Chemical Communications, 3(2), 2013,133-140.

[2]. M.P. Prasad, P. Bhakat, and S. Chatterjee , Optimization of textile dye degradation by bacterial species isolated from natural sources, Journal of Ecology and Environmental Sciences, 4(1), 2013, 97-99.

[3]. K.V. Kumar, and A. Kumaran, Removal of methylene blue by mango seed kernel powder, Biochemical Engineering Journal, 27(1), 2005, 83-93.

[4]. K.V. Kumar, V. Ramamurthi and S. Sivanesan, Modeling the mechanism involved during the sorption of methylene blue onto fly ash, Journal of Colloid and Interface Science, 284(1), 2005, 14-21.

[5]. R. Han, Y. Wang, P. Han, J. Shi, J. Yang, and Y. Lu, Removal of methylene blue from aqueous solution by chaff in batch mode, Journal of Hazardous Materials, 137(1), 2006, 550-557. 
[6]. Z. Al-Qodah, Adsorption of dyes using shale oil ash, Water Research, 34(17), 2000, 4295-4303

[7]. P. Woodberry, G. Stevens, I. Snape, and S. Stark, Removal of metal contaminants by ion-exchange resin columns, Thala Valley tip, Casey Station, Antarctica, Solvent Extraction and Ion Exchange, 24(4), 2006, 603-620.

[8]. S. Siji, M.A. Dhanitha and C. Janardanan, Efficient Degradation of Dyes in Water by a Novel Inorganic Cation Exchanger Cerium(IV) arsenomolybdate, Journal of Environmental Nanotechnology, 2(2), 2013, 81-87.

[9]. D. Mahanta, G. Madras, S. Radhakrishnan, and S. Patil, Adsorption and desorption kinetics of anionic dyes on doped polyaniline, Journal of Physical Chemistry B, 113(8), 2009, 2293-2299.

[10]. C.N.R. Rao, Chemical Applications of Infrared Spectroscopy (Academic Press, New York, 355, 1963).

[11]. F. Monroy-Guzman, V. Diaz-Archundia, and A. Contreras Ramírez, Effect of Zr:mo ratio on $99 \mathrm{mTc}$ generator performance based on zirconium molybdate gels, Applied Radiation and Isotopes, 59(1), 2003, 27-34.

[12]. J. Chalmer and P.Griffths, Handbook of Vibrational Spectroscopy. (John Wiley \& Sons, Chinchest U.K., 2001)

[13]. Parimal Patel and Uma Chudasama, Thermodynamics and kinetics of ion exchange using titanium diethylene triamine pentamethylene phosphonate - a hybrid cation exchanger, Journal of Scientific \& Industrial Research, 69(10), 2010, 756-766.

[14]. K. Harish Sharma and Nadeem Sharma, Synthesis and structural characterization of Tin (IV) Molybdotungstate-A Heteropolyacid Salt, Pelagia Research Library, Der Chemica Sinica, 4(2), 2013, 82-188.

[15]. J. Raffiea Baseri, P.N Palanisamy and P. Siva Kumar, Adsorption of Basic Dyes from synthetic Textile effluent Activated Carbon Prepared from Thevetia Peruviana, Indian Journal of Chemical Technology, 19(5), 2012, 311-321.

[16]. N. Kannan and M.M. Sundaram, Kinetics and mechanism of removal of methylene blue by adsorption on various carbons- a comparative study, Dyes and Pigments, 51(1), 2001, 25-40.

[17]. Weber Jr. WJ. ( Physico-chemical processes for water quality control, (New York; Wiley Inter Science, 1972)

[18]. C. A. P. Almeida, N. A. Debacher, A. J. Downs, L. Cottet, and C. A. D.Mello, Removal of methylene blue fromcolored effluents by adsorption on montmorillonite clay, Journal of Colloid and Interface Science, 332(1), 2009, 46-53.

[19]. B. H. Hameed,"Equilibriumand kinetic studies of methyl violet sorption by agricultural waste," Journal of Hazardous Materials, 154(1-3), 2008, 204-212.

[20]. P. Waranusantigul, P. Pokethitiyook, M. Kruatrachue and E.S. Upatham, Kinetics of basic dye (methylene blue) biosorption by giant duckweed (spirodela polyrrhiza)', Environmental Pollution, 125(3), 2003, 385-392.

[21]. T. Shahwan and H.N. Erten, Thermodynamic parameters of $\mathrm{Cs}^{+}$sorption on natural clays, Journal of Radioananalytical and Nuclear Chemistry, 253 (1), 2002, 115-120.

[22]. I.A.W. Tan, A.L. Ahmad, B.H. Hameed, Adsorption of basic dye on high-surface-area activated carbon prepared from coconut husk: Equilibrium, kinetic and thermodynamic studies, Journal of Harzardous Materials 154(1), 2008, 337-346.

[23]. M.S. Mansour, M.E. Ossman and H.A. Farag, Removal of Cd (II) ion from waste water by adsorption onto polyaniline coated on sawdust, Desalination, 272(1), 2011, 301-305

[24]. Y.S. Ho, Adsorption of heavy metals from waste streams by peat, doctoral diss, The University of Birmingham, Birmingham, U.K. (1995).

[25]. S. Chen, J. Zhang, C. Zhang, Q. Yue, Y. Li and C. Li, Equilibrium and Kinetic studies of methyl orange methyl violet adsorption on activated carbon derived from Phragmites australis., Desalination, 252(1-3), 2010, 149-156.

[26]. Y.S. Ho, G. Mckay, Kinetic models for the sorption of dye from aqueous solution by wood. Process Safety and Environmental Protection, Chemical Engineering Journal, 76 B(1), 1998, 183-191.

[27]. M.S. Chiou,P. Ho, Y. Ho and H.Y. Li, Adsorption of anionic dyes in acid solutions using chemically cross-linked chitosan beads, Dyes Pigments, 60(1), 2004, 69-84.

[28]. A.E. Ofomaja and Y.S. Ho, Equilibrium sorption of anionic dye from aqueous solution by palm kernel fibre as sorbent. Dyes and Pigments, 74 (1), 2007, 60-66. 